\title{
"PONHA OS OLHOS EM MIM": sobre direitos humanos e memórias de luta das mulheres escravizadas no Brasil
}

\author{
CLÁUDIA MIRANDA
}

Doutora em Educação (PROPEd/UERJ), É professora associada do Departamento de Didática e do Programa de Pós-Graduação da UNIRIO. Coordena os projetos de pesquisa Intercâmbio

Colômbia - Brasil: experimentos afrolatinos e diálogos interculturais na produção do conhecimento refletida nas políticas curriculares e o projeto Como a Educação Intercultural impacta as políticas e as práticas curriculares no Brasil e na Colômbia: um estudo comparado

sobre a participação do Grupo de Trabalho da CLACSO Afrodescendiente (2017/2019) movimentos pedagógicos e as perspectivas de gestores/as e etnoeducadores/as. ORCID: 00000001-6105-6356. E-mail: mirandaunirio@gmail.com

\section{CARLA SILVA}

Mestre em Educação (PPGEdu/UNIRIO). ORCID: 0000-0002-4926-9401.

Email: carla_silva@ymail.com 


\section{"PONHA OS OLHOS EM MIM": sobre direitos humanos e memórias de luta das mulheres escravizadas no Brasil}

O objetivo deste trabalho é apresentar a partir das performances de Esperança Garcia e Gertrudes Maria, a construção de aprendizagens outras de luta, resistência e conquista de direitos para a população negra brasileira. Nessa perspectiva consideramos como objeto de análise os materiais de memória coletiva como a carta escrita em 6 de setembro de 1770, endereçada ao Governador da Província do Piauí Gonçalo Lourenço Botelho de Castro, relatando toda violência física e simbólica sofrida juntamente com seus filhos e suas companheiras. Do mesmo modo, consideramos a apelação Cível à penhora de Gertrudes entre os anos de 1828 a 1842. São duas histórias que compõem um quadro de resistência frente às formas de violação sofrida. Essas agências nos ajudam a entender o protagonismo de sujeitas escravizadas e a construir uma outra memória sobre a sua participação na sociedade.

Palavras-Chave: Esperança Garcia. Gertrude Maria. Agência Política. Escravização.

\section{"PUT YOUR EYES ON ME": on human rights and memory of slaved women strugle in Brazil}

The objective of this work is to present, from the performances of Esperança Garcia and Gertrudes Maria, the construction of other learning of struggle, resistance and conquest of rights for the Brazilian black population. In this perspective we consider as object of analysis the materials of collective memory like the letter written on September 6, 1770, addressed to the Governor of the Province of Piauí Gonçalo Lourenço Botelho de Castro, reporting all physical and symbolic violence suffered along with his children and their companions . Likewise, we considered the Civil Appeal to Gertrude's attachment between the years 1828 to 1842 . These are two stories that form a framework of resistance to the forms of violation suffered. These agencies help us understand the protagonism of enslaved subjects and build another memory about their participation in society.

Keywords: Hope Garcia. Gertrude Maria. Political Agency. Enslavement.

\section{"PONGA LOS OJOS EN MÍ": sobre derechos humanos y memorias de lucha de las mujeres esclavizadas en Brasil}

El objetivo de este trabajo es presentar a partir de las performances de Esperanza García y Gertrudes Maria, la construcción de aprendizajes otras de lucha, resistencia y conquista de derechos para la población negra brasileña. En esa perspectiva consideramos como objeto de análisis los materiales de memoria colectiva como la carta escrita el 6 de septiembre de 1770, dirigida al Gobernador de la Provincia del Piauí Gonçalo Lourenço Botelho de Castro, relatando toda violencia física y simbólica sufrida junto con sus hijos y sus compañeras . De la misma manera, consideramos la apelación Civil al embargo de Gertrudis entre los años 1828 a 1842. Son dos historias que componen un cuadro de resistencia frente a las formas de violación sufrida. Estas agencias nos ayudan a entender el protagonismo de sujetas esclavizadas ya construir otra memoria sobre su participación en la sociedad.

Palabras clave: Esperanza García. Gertrude Maria. Agencia Política. Esclavización. 


\section{"PONHA OS OLHOS EM MIM": sobre direitos humanos e memórias de luta das mulheres escravizadas no Brasil}

\section{Introdução}

Dados atuais sobre as condições e qualidade de vida das mulheres no Brasil, apontam índices consideráveis sobre as desigualdades, sobretudo, quando se comparam as condições de vida de mulheres brancas e de mulheres negras. No campo educacional a desigualdade, segundo sua cor ou raça, é de $23,5 \%$. Brancas, com ensino superior completo, apresentam um percentual de 2,3 vezes maior que o percentual de mulheres pretas ou pardas (10,4\%), que chegam a concluir a graduação. (IBGE, 2018). Dados da Pesquisa Nacional de Saúde (PNS) de 2013 mostram que, na divisão por cor e raça, ambos indicadores, sobre atendimento em consulta pré-natal, apresentam desigualdades: enquanto $98,6 \%$ das mulheres brancas foram atendidas em, no mínimo, uma consulta com profissional de saúde especializado, na última gravidez, entre as pretas ou pardas, esse percentual foi menor: $96,6 \%$.

Diante deste quadro, importa reconsiderar a urgência de políticas de equidade para garantir os direitos das mulheres. A promoção e o estabelecimento do acesso a direitos justos para todas as pessoas, independente de raça, sexo, nacionalidade, etnia, idioma, religião ou qualquer outra condição, tem sido, de fato, um exercício contínuo na sociedade contemporânea. Alargar esses direitos entre os grupos subrepresentados - comunidades LGBT, mulheres, negras/os e crianças -, e que sofrem ações de diferentes formas de violação de seus corpos, tem sido pauta prioritária nas agendas dos movimentos sociais. Os direitos humanos envolvem principalmente o direito à vida e à liberdade, à liberdade de opinião e de expressão, direito ao trabalho, à saúde e à educação. Portanto, para os estudos sobre os direitos humanos na educação, é necessário um recorte racial, é necessário debatermos as causas e as consequências desse panorama.

Nossas pesquisas sobre desigualdade de gênero e sobre luta antirracista nos levaram ao tema da reinvenção de si, de mulheres escravizadas. As trajetórias de Esperança Garcia e de Gertrudes Maria estão marcadas pela agência ${ }^{1}$ política em contexto de escravização. Referimo-nos a duas

\footnotetext{
${ }^{1}$ Agência' não se refere às intenções que as pessoas têm ao fazer as coisas, mas à capacidade delas para realizar essas coisas em primeiro lugar (sendo por isso que 'agência' subentende poder: cf. uma definição de agente do Oxford English Dicitionary como 'alguém que exerce poder ou produz um efeito'). 'Agência' diz respeito a eventos dos quais um indivíduo é o perpetuador, no sentido de que ele poderia, em qualquer fase de uma dada sequencia de conduta, ter atuado de modo diferente. O que quer que tenha acontecido não o teria se esse indivíduo não tivesse interferido. A ação é um processo contínuo, um fluxo, em que a monitoração reflexiva que o indivíduo mantém é fundamental para
}

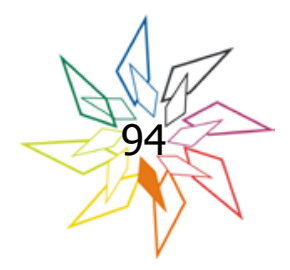


pessoas que viveram na condição de escravizadas e mesmo sob essa absoluta violação de sua existência, realizaram feitos de impacto para a coletividade e resistiram a processos violentos - tanto psíquicos como físicos. Suas práticas discursivas foram inseridas, nesse trabalho, com o propósito de analisarmos práticas de intervenção social e aspectos da agência política. $O$ foco está nas estratégias de denúncia, por parte de sujeitas negras - africanas e afro-brasileiras que são importantes presenças na memória de luta dos afro-brasileiros e das afro brasileiras. Adotamos, como aporte teórico, a perspectiva da história social e do pensamento decolonial na América Latina, para discutir os conceitos de memória, gênero e raça, no intento de abordar o lugar da mulher escravizada na historiografia oficial e na proposição de "aprendizagens decoloniais" (grifos nossos).

Podemos supor que esses são episódios históricos de insurgência negra na qual se analisa a escrita como uma forma de mobilização também coletiva. A tomada de posição ao produzirem discursos contra hegemônicos é, portanto, reflexo da ética fanoniana ${ }^{2}$ sendo, portanto, ações não só para si, mais para as famílias escravizadas e a comunidade formada no entorno. E por criar uma rede de proteção, de solidariedade e, ainda, de sentido comum.

Recuperar as estratégias performáticas de sujeitas negras, passa a ser um exercício de justiça social, mas sobretudo uma metodologia para desclandestinizar a existência na Diáspora Africana. A disputa epistemológica da qual fazemos parte, implica revermos as referências legitimadas para o campo das Ciências Sociais e para o campo da Educação. Nessas áreas, alguns grupos de investigadoras/es têm indicado esses percursos de insurgência e suas imbricações. Em destaque estão autoras como: Joselina da Silva (2009, 2018), Solange Pereira da Rocha (2001), Conceição Evaristo (2007), entre muitas outras. Problematizar os aspectos que trabalharam em sua produção, é, por exemplo, participar de uma política de citação onde essa produção muda de status. E, ao mesmo tempo, é provocar uma reflexão sobre como é fundamental reconhecer processos de violação de subjetividades clandestinizadas de segmentos inteiros que fazem parte da Diáspora Africana. Não obstante, a condição de clandestinização ${ }^{3}$ de mulheres escravizadas deve ser melhor estudada.

\footnotetext{
${ }^{2}$ A ética fanoniana é entendida como um modo insurgente e libertador de viver e de reivindicar a existência diante das violações coloniais. Sobre isso, indicamos a obra "Peles negras, máscaras brancas" de Frantz Omar Fanon (2008).

${ }^{3}$ Adotamos o conceito de "clandestinização" desenvolvido por Santiago Arboleda Quiñonez (2016). O autor problematiza a dimensão da violência epistemológica produzida por distintos níveis de ambigüidade, apagamento e negação.
} 
As mulheres escravizadas, no Brasil, estão presentes em fotografias e em recomposição de cenários que reforçam, de algum modo, o seu não lugar como humana. A historiografia brasileira é desafiada a rever os percursos das referências produzidas sobre as populações africanas presentes no país e a considerar episódios significativos, mas que foram, estrategicamente, desconsiderados como relevantes. Suas performances indicam posicionamento político e iniciativas que alimentaram outras demandas grupais. Estão em destaque, portanto, documentos que provocam dinâmicas próprias de mobilização - ainda que desprezadas como memória social.

A ideia de agência política, apresentada por Giddens (2009), traduz o lugar das ações de enfrentamento e interferência desses estratos deshumanizados, diante de uma realidade que se apresentava violenta e excludente:

Dentro dos limites da informação, da incerteza e de outras restrições (físicas, normativas ou político-econômicas) existentes, os atores sociais são "detentores de conhecimento" e "capazes". Eles procuram resolver problemas, aprender como intervir no fluxo de eventos sociais ao seu entorno e monitorar continuamente suas próprias ações, observando como os outros reagem ao seu comportamento e percebendo as várias circunstâncias inesperadas (GIDDENS, 2009, p. 1-6).

Ao apresentar resultados de sua pesquisa sobre pensamento intelectual afro colombiano, Santiago Arboleda Quiñonez (2016, p.84-85) sugere pistas sobre a luta da Diáspora Africana para rever a historiografia oficial,

La agencia sin consecuencias de la historicidad del pensamiento y de la reflexión intelectual de los sujetos, produce una imagen, un reflejo de activismo, de acciones inconexas; representación distorsionada en la cual se encuentra atrapada el afrocolombiano, construido por estas disciplinas en el país que se proyecta en el ámbito institucional de la escuela, el colegio, la universidad y el Estado en su conjunto; produciendo con tal silenciamiento, el mensaje de que los afrocolombianos no han pensado, no piensan, y si acaso lo han hecho, ha sido muy poco y siempre al servicio de su inmediatez en la sobrevivencia.

Esses são elementos que emergiram de leituras obrigatórias sobre as disputas epistemológicas em curso. Tomamos alguns aspectos centrais das trajetórias de Esperança Garcia e Gertrudes 
Maria como mote, para recompormos as linhas de pesquisas sobre narrativas subalternas. Visase, portanto, compreender estratégias de insurgência nos espaços sociais e políticos, onde se disputam epistemologias, e projeto alternativos de desaprendizagens e de reaprendizagens com os diferentes agrupamentos em formação.

O Plano Nacional de Implementação das Diretrizes Curriculares para a Educação das Relações Étnico-raciais e para o ensino de História e Culturas Afro-brasileira e Africana (2008) incluiu, como parte dos seus objetivos, desenvolver ações estratégicas para a formação de professores, e visa proporcionar o conhecimento e a valorização da história das/os africanas/ os e da cultura afro-brasileira. Também visa o desenvolvimento de pesquisas e de materiais pedagógicos que valorizem a cultura afro-brasileira. Ao insistirmos com a inclusão de outros discursos sobre o protagonismo de estratos sociais invisibilizados, atentamo-nos para as urgências indicadas no plano e nos seus objetivos.

Considerando que o processo de colonização e de escravidão no Brasil é um fenômeno que ainda influencia a construção das identidades nacionais, podemos observar, com Joselina da Silva (2009), aspectos importantes sobre o papel dessas mediadoras na transposição de conhecimentos políticos, socioculturais e religiosos. Para a autora:

Ao falar das Filhas da Diáspora, observaremos como ao longo da história social brasileira essas mulheres foram guardiãs de suas identidades culturais e guerreiras na luta por seus direitos. Nascidas no Brasil, estas mulheres têm, por caminhos diversos, legados às gerações seguintes afazeres e pensamentos que até hoje causam sentimento de orgulho e compromisso diante de nossa identidade africana, latina e américa. (SILVA, 2009, p. 08).

Com essa afirmação, vimos que a relação entre memória, passado e presente está no centro das análises subsequentes e indicam como é possível examinar nuances do lugar de enunciação negado na historiografia oficial.

As memórias podem ser consideradas como uma caixa em que se guardam objetos especiais e de grande valor e, com o passar do tempo, alguns objetos podem ser retirados e outros adquiridos. Assim, a caixa vai se tornando um lugar de muitas lembranças - sejam boas ou ruins. A opção que fazemos é de revisão dos artefatos culturais para fomentar justiça epistemológica, se consideramos como indispensável, o que aponta o Plano Nacional de Implementação das 
Diretrizes Curriculares para a Educação das Relações Étnico-raciais e para o ensino de História e Culturas Afro-brasileira e Africana (2008).

Em seu livro Ensinando a transgredir: a educação como prática da liberdade, Bell Hooks (2017) afirma que não é fácil dar nome às nossas dores e nem criar teorias a partir desse lugar. Mas, é dentro desses espaços que emergem movimentos de resistência, sabendo que essas narrativas construídas nos conflitos, servem de exemplo e apoiam a construção do pertencimento identitário, principalmente, da mulher negra. Neste sentido, entendemos como elucidativo, o referencial teóricoepistemológico pautado nos estudos da história social e da perspectiva do pensamento decolonial na América Latina, como fonte de inspiração para uma abordagem que favoreça contra narrativas e rupturas com o sistema de inspiração colonial de exploração e controle.

\section{Memórias anônimas}

De acordo com Le Goff (2013), a memória se caracteriza como um fenômeno individual e psicológico que está ligado à vida social, que conserva informações e impressões do passado. Dessa forma, podemos compreender que as memórias individuais e também coletivas, permitem visitar um passado e lembrar os processos históricos que já foram vividos em todas as suas complexidades, criando pontes que permitem ultrapassarmos as fronteiras de uma temporalidade dimensional que acessa outras existências, outras histórias, permitindo compor novas formas de existir.

Na historiografia brasileira existem lacunas consideráveis sobre as relações de gênero e de raça, no período escravista (GOMES e SCHWAARCZ, 2018). De alguns estudos, destacamos relatos estereotipados como as negras são representadas como "trabalhadoras domésticas" e/ou como personagens “erotizadas". Para Angela Davis (2016): "se, e quando alguém conseguir acabar, do ponto de vista histórico, com os mal-entendidos sobre as experiências das mulheres negras escravizadas, [...] terá prestado um serviço inestimável" (DAVIS, 2016, p. 17). E nessa direção, Marcelo Paixão e Flávio Gomes (2008) salientam,

A Há silêncios na história de ontem e de hoje; sobre o papel das relações de gênero e raça no passado escravista - entre a imagem de mucamas e a suposta permissividade sexual - nas primeiras décadas da abolição com a estigmatização e a erotização do corpo da mulher negra; e no tempo presente em que indicadores sociais apontam desigualdades no mercado de trabalho e preponderância feminina na chefia dos domicílios das grandes regiões metropolitanas. Embora os estudos sobre gênero tenham ampliado horizontes e eixos teórico-metodológicos, ainda pouco conhecemos a respeito das conexões históricas entre raça e gênero. As reflexões sobre as experiências das mulheres negras nas comunidades escravas e nas primeiras décadas da pós-emancipação no Brasil continuam ausentes. (PAIXÃO E GOMES, 2008, p 949-950). 
As mulheres negras não foram personagens que figuravam inertes e acomodadas na sua vida de escravidão, "as mulheres resistiam e desafiavam a escravidão o tempo todo" (DAVIS, 2016, p.18), sendo conhecidas por sua força e poder espiritual. Muitos relatos mostram ações pontuais de coragem e força dessas mulheres,

Em muitos casos, a resistência envolvia ações mais sutis do que revoltas, fugas e sabotagens. Incluía, aprender a ler e a escrever de forma clandestina, bem como transmissão desse conhecimento aos demais. Em Natchez, Lousiana, uma escrava comandava uma "escola noturna", dando aulas a seu povo das onze horas às duas da manhã, de maneira que conseguiu "formar" centenas de pessoas (DAVIS, 2016, p.34).

Na medida em que essas narrativas surgem como memórias individuais, nesse espaço do tempo presente, essas ganham status de memórias coletivas por transmitir "lembranças que não vem de uma experiência direta, mas sim da experiência dos outros" (SARLO, 2017, p.97). Isso é o que Sarlo (2007) vai chamar de "pós memória", considerando esse "lembrar" como,

[...] a geração seguinte àquela que protagonizou os acontecimentos, ou seja, é a memória dos filhos sobre a memória dos pais. [...] a pós memória cumpre as mesmas funções clássicas da memória: fundar um presente em relação com um passado. A relação com esse passado não é diretamente pessoal, em termos de família e pertencimento, mas se dá através do público e da memória coletiva produzida institucionalmente. (SARLO, 2017, p.97).

As inquietações que nos movem estão relacionadas com materiais de memórias coletivas (LE GOFF, 2013), apresentados aqui pelos "textos insurgentes" (grifos nossos) - a carta de Esperança Garcia e a apelação de Gertrudes Maria. São memórias que se materializam através de documentos, atos escritos que testemunham traços da história contada, que recordam as relações sociais vividas e materializam a capacidade que mulheres negras apresentam de se reinventarem diante dos confrontos diários. Uma memória coletiva que aponta perspectivas outras de reinvenção. Esse é um "fator extremamente importante do sentimento de continuidade e de coerência de uma pessoa ou de um grupo em sua reconstrução de si” (SARLO, 2007, p. 98).

Por tudo isso, ao analisarmos as narrativas históricas das escravizadas, aqui citadas, nos confrontamos com as experiências de mulheres negras que viveram dentro de um sistema opressor 
que definia toda população negra como propriedade, que interrompia seus corpos transformados em mercadoria. Frente a tudo que mencionamos, somos um corpo da resistência e de poder político. Um corpo insurgente que resiste e que vira sementes, que desperta consciência de que somos parte de um "ethos diaspórico" (grifos nossos) pela vinculação com África; mas, também, pela condição de reinvenção de si fora do território de origem.

Ao pensarmos com Silva, sobre a invisibilidade da agência política, das mulheres negras, destacamos a seguinte questão,

Um breve olhar na história das mulheres negras revela diferentes marcos e fontes a considerar, ainda mais quando se pretende abordar a organização social de mulheres e homens negros no Brasil. Nesse panorama, a abolição da escravatura (1888) e o advento da República (1889), sem dúvida, podem ser levados em conta. Deixando à margem das benesses advindas destes dois fatos históricos e, por muitos anos, do processo decisório nacional, mulheres e homens negros organizaram-se e reagiram apesar das diferentes discriminações (SILVA, 2009, p. 10)

Construir outras agendas, a partir de uma leitura decolonial, em diálogo com narrativas femininas, que ultrapassam as fronteiras do não-lugar, nos ajuda a pensar outros projetos de sociedade e a localizar o importante papel que desempenharam Esperança Garcia e Gertrudes Maria. Vimos, com suas performances, que é possível reinventar nossa agência política e nesse sentido, pensar a partir da crítica decolonial latino-americana, nos ajuda a retomar o caminho da história não contada, dos corpos e mentes não escravizados que as formas de invisibilização dos não europeus, nos fez desconsiderar. Podemos considerar que a dimensão educativa das suas performances, atravessa o movimento existente incluindo a memória, o passado e o presente. Favorece a compreensão e aproximação do lugar ocupado pela "negra escravizada-insurgente" (grifos nossos) e os desafios de reexistir com as condições apresentadas à época. Nas análises de Davis, "A julgar pela crescente ideologia do século XIX, que enfatizava o papel das mulheres como mães protetoras, parceiras e donas de casa amáveis para seus maridos, as mulheres negras era praticamente anomalias". (DAVIS, p. 17-18, 2016).

Torna-se relevante pensar nos processos de re-existência desses corpos e as saídas para a recomposição de si. Estar no mundo com as memórias coletivas de resistência negra e feminina, é diferente de estar sem referências de luta. Que romperam com as concepções sociais e jurídicas vigentes em seu tempo, seguindo pelas brechas, por "lugares e espaços a partir do qual a ação, 
militância, a resistência, insurgência e transgressão são impulsionadas, onde as alianças se constroem, e surge um modo-outro que se inventa, cria e constrói” (WALSH, p. 72, 2009).

\section{Pelo direito à reinvenção da vida}

Existe um grande número de acervo documental incluindo cartas, recibos de compra e venda, relatos de viagens, imagens e quadros e fotografias que possibilitam construir um mosaico do que foi o período de escravidão e pós-abolição no Brasil. Desses registros saem narrativas importantes para a reconstrução de um passado que está presente e que nos coloca em proximidade com pessoas e experiências de um outro tempo e espaço que está sempre em movimento. Conforme Sarlo, "A narração inscreve a experiência numa temporalidade que não é a de seu acontecer [...], mas a de sua lembrança. A narração também funda uma temporalidade, que a cada repetição e a cada variante torna a se atualizar". (SARLO, 2007, p.2).

Desse apontamento memorativo que trazemos, pelas narrativas de Esperança Garcia e Gertrudes Maria, emergem aprendizagens sobre re-existência, re-significação e reinvenção de luta. Emergem práticas de reivindicação de direitos para as mulheres escravizadas e para as suas famílias. Trazer a memória o protagonismo nas próprias escravizadas, na luta abolicionista e no campo de pesquisa sobre direitos humanos para as negras, se torna indispensável tendo em vista o cenário que enfrentamos de recomposição de direitos perdidos. Suas ações ganham destaque e referência na promoção da igualdade de direitos, combate ao racismo, combate aos processos violentos que tem atingido, sobremaneira, a população feminina e negra em todo o globo. Em outras palavras, conforme a afirmativa de Claudia Miranda (2013, p.103), "as trajetórias dos sujeitos representados como o 'diferente' da colonização passam a ganhar relevo, bem como suas ancestralidades, tendo em vista os objetivos da agenda antirracista a qual nos referimos". Sua análise é pautada na possibilidade de se "trilhar percursos que incluam a experiência com as práticas de aprender juntos/as no que concerne aos desafios de desaprender para reaprender novamente as multiplicidades que nos definem como sujeitos". (Ibidem).

A criação de pautas normativas voltadas para os direitos humanos é recente. Os conflitos militares, durante a Segunda Guerra Mundial ${ }^{4}$ motivou a criação da Organização das Nações Unidas (ONU), com o fim de proteger as nações de novos conflitos. O compromisso da ONU

\footnotetext{
${ }^{4}$ Segunda Guerra Mundial (1939-1945), conflito militar entre a maioria das nações no mundo, incluíndo as grandes potências como Alemanha, Polônia, Itália, Japão, Grã-Bretanha, França, e Estados Unidos.
} 
de garantir uma vida justa e segura para cidadãs e cidadãos começa na década de 40. Diante dessa prerrogativa, os países membros se apoiam na Declaração dos Direitos Humanos para estabelecer seus compromissos frente a sua criação e validade. Direitos que estão relacionados com a manutenção da paz nacional e a eliminação das desigualdades diversas.

Em 1946, são incorporados à Declaração alguns tratados na garantia da ampliação dos direitos humanos, entre eles estão Convenção para a Prevenção e a Repressão do Crime de Genocídio (1948), a Convenção Internacional sobre a Eliminação de Todas as Formas de Discriminação Racial (1965), a Convenção sobre a Eliminação de Todas as Formas de Discriminação contra as Mulheres (1979), a Convenção sobre os Direitos da Criança(1989) e a Convenção sobre os Direitos das Pessoas com Deficiência (2006), entre outras. A Convenção sobre a Eliminação de Todas as Formas de Discriminação contra as Mulheres (1979), tem seu conteúdo específico a fim de garantir a igualdade de gênero e o documento se estende por todos os países-membros da ONU, e no Brasil ele ganha status normativo através do Decreto Executivo $\mathrm{N}^{\mathrm{o}} 4.3777$ de 13 de setembro de 2002. A constar,

Artigo $1^{\circ}$ : Para os fins da presente Convenção, a expressão "discriminação contra a mulher" significará toda a distinção, exclusão ou restrição baseada no sexo e que tenha por objeto ou resultado prejudicar ou anular o reconhecimento, gozo ou exercício pela mulher, independentemente de seu estado civil, com base na igualdade do homem e da mulher, dos direitos humanos e liberdades fundamentais nos campos político, econômico, social, cultural e civil ou em qualquer outro campo. (BRASIL, 2002).

Algumas indagações devem ser feitas quando discutimos direitos. E, quando analisamos questões que envolvem "direitos humanos de mulheres", sobre quais mulheres falamos? Quais são as imagens que chegam nas representações que construímos? De que mulheres lembramos? $\mathrm{O}$ dia 8 de março, conhecido como o Dia Internacional das Mulheres, é um exemplo de como a sociedade tem pensado os direitos para essa mulher. As hipóteses que emergiram quando discutimos os direitos humanos de mulheres, estão relacionadas com as leituras que fazemos sobre a pluralidade dos feminismos. Onde está a mulher negra, na luta feminista do ocidente? Quais questões refletem a preocupação com as outras mulheres - as não europeias de diferentes lugares do mundo? Se fôssemos construir uma linha do tempo com os eventos que marcaram essa 
data, teríamos dois eventos historicamente conhecidos, em que todos estão relacionados a luta e reivindicações de mulheres por melhores condições de trabalho.

Em 8 de março de 1857, 129 mulheres foram queimadas por policiais numa fábrica têxtil por reivindicarem a redução da jornada de trabalho e pelo direito da licença maternidade ${ }^{5}$. Em 1910 em Copenhague, na Dinamarca, na II Conferência Internacional de Mulheres, é proclamado o dia internacional das mulheres em memórias das operárias mortas em Nova Iorque em 1985. E no Brasil? Como estava a luta das mulheres em 1857 e/ou nos anos seguinte?

As lutas abolicionistas no Brasil ocorreram de modo lento e gradual, o Brasil foi o último país a promulgar a lei que abolia a escravidão, Lei Aurea de 1888, um processo que foi se desfigurando devagar, principalmente no interior das cidades onde os grandes fazendeiros dependiam do trabalho escravo para manter suas produções. Logo, em 1857 as mulheres negras ainda eram escravizadas. Estavam nas lavouras, na casa grande, nas senzalas, nas ruas, produzindo sem descanso devido, sem benefícios, sem alimentação adequada. As mulheres negras escravizadas - ou mesmo as libertas - resistiam um dia de cada vez. As mulheres negras se organizavam e lutavam de diferentes formas, por seus direitos, como escravizadas. E mesmo quando não tinham o reconhecimento e status de cidadãs, imprimiram estratégias exemplares de reinvenção de si. Participaram de movimentos que nasceram da sobrevivência dos tumbeiros, ou da própria terra de Vera Cruz. É dessa terra preta e vermelha que nascem, também, as narrativa de Esperança Garcia e Gertrudes Maria.

\section{Esperança Garcia}

Esperança Garcia foi uma mulher negra escravizada que empreendeu, com ousadia e coragem uma luta que, a nosso ver, foi por direitos humanos. Em 1770 escreveu uma carta endereçada ao Governador da Província do Piauí Gonçalo Lourenço Botelho de Castro denunciando os maus tratos que recebia junto aos seus filhos, além de reivindicar o direito de retorno junto ao seu marido - pois foi retirada a força da fazenda onde viviam - e reivindicar o direito de exercer sua religiosidade batizando seus filhos na Igreja Católica. Viveu na região de Oeiras, na fazenda de Algodões, localizada a mais ou menos $300 \mathrm{~km}$ de Teresina. A propriedade pertencia à Inspeção de Nazaré, onde é hoje o município de Nazaré do Piauí. Abaixo, reproduzimos a carta de Esperança em sua escrita original (1770),

\footnotetext{
${ }^{5}$ Jornal Folha de São Paulo, 2017
} 


\begin{abstract}
Eu sou qua escrawa de O. Sa. administração de Capam. Ant ${ }^{\theta}$ Oieira de Couto, cazada. Desde que o Capam. lá foi adeministrar, q. me tirou da fazenda dos algodois, aonde vevia com meu marido, para ser cozinheira de sua caza, onde nella passo mto mal. A primeira hé q. ha grandes trovoadas de pancadas em hum filho nem sendo uhã criança $q$. The fez estrair sangue pella boca, em mim não poço esplicar $q$. sou hu colcham de pancadas, tanto $q$. cahy huã vez do sobrado abaccho peiada, por mezericordia de Ds. esCapei. A segunda estow ew e mais minhas parceiras por confeçar a tres annos. E huã criança minha e duas mais por batizar. Pello q. Peço a l.S. pello amor de Ds. e do seu Ualimto. ponha aos olhos em mim ordinando digo mandar a Procurador que mande p. a fazda. aonde elle me tirou pa en viver com meu marido e batizar minha filha $q$.
\end{abstract}

De U.Sa. sua escrawa Esperança Garcia

A autora da carta aprendeu a ler e a escrever numa época em que as mulheres não tinham esse direito; principalmente, as que faziam parte da população escravizada. Acreditamos que, pelo fato de ter nascimento em uma fazenda comandada pelos padres jesuítas, foi possível seu acesso ao mundo letrado quando criança, conforme a percepção de Elio Ferreira (2015),

Cogitamos que Esperança Garcia aprendera a ler e escrever com os padres Jesuítas ou com pessoas relacionadas a eles, de quem fora escrava, antes da expulsão desses sacerdotes por Pombal. Uma vez expulsa a Companhia, as fazendas se tornaram propriedades da Coroa de Portugal. O manuscrito da Carta, escrita pela própria Esperança, a escrava insurgente, foi dirigida ao Governador da Capitania, conforme transcrição fidedigna do referido relato (MOTT, 1985 - 2010).

A carta de Esperança Garcia é mais que um relato de violência; essa narrativa aparece, a nosso ver, como uma estratégia de luta a fim de resistir e sobreviver ao sofrimento. Ao considerarmos a fixação dada às mulheres, em sentido amplo, no século XVIII, podemos supor que as escravizadas recriaram suas subjetividades mesmo como deslocadas de seus territórios de origem e afastadas de suas culturas. Em um exercício de transgressão absoluta de protagonismo social, promoveram insurgência sem garantia de resultados exitosos. Encontraram fios de possibilidades de questionar os direitos da população escravizada e os casos mencionados aqui, são exemplos de desobediência e deslocamento. 
Pensar essas possibilidades de movimentação e "ter a consciência de seu enorme poder - sua capacidade de produzir e criar". Esperança escreve a carta e denuncia o seu agressor e ao mesmo tempo reclama o direito de viver sua religiosidade - batizar a filha além de solicitar o retorno para a fazenda junto ao seu marido. Seu argumento é pela coletividade quando sua petição se estende às companheiras. Vimos, nessa inclinação, a expressão ativista em um contexto de negação de pertencimento. Nesse enviesamento, luta por seus direitos sabendo que, como escravizada, era "não cidadã". Após oito anos da petição, Esperança continuou a se mobilizar, conseguindo fugir, supomos que essa decisão tenha sido pela falta de resposta ou pela resposta negativa a sua carta. Elio Ferreira de Souza (2015) reproduz um fragmento do registro feito pelo poder público sob sua situação:

\begin{abstract}
Conta que dou a l. As. Da residência de Sazaré, que é procurador o Capitão Antônio lieira do Couto: (ele) tirou uma escrava chamada Esperança, casada, da fazenda de Algodões e não tem concedido tempo algum para a dita ir fazer vida com seu marido, vendo apertada com vários castigos tem fugido por várias vezes e $\theta$ dito Capitão tem posto tão timida a dita em forma uma quinta feira deu tanta bordoada com um pau e com ela no chão e depois jurou que havia de amarrar dita escrava se erretirou com os dois filhos, um nos braços, de 7 meses e outro de 3 anos; o presente não tem tido noticia dela.
\end{abstract}

O relato parece indicar a acolhida da denúncia feita na carta escrita por Esperança Garcia. A autora entendeu que, por si só, não conseguiria mudar as condições concretas de violência que sofria naquele ambiente hostil e desumanizador. Não obstante, ela tinha planos maiores para si e para a sua família e estava determinada a resistir. Conforme se vê, Esperança Garcia fugiu.

As narrativas históricas, produzidas pela então denunciante, nos levam para outras indagações sobre insurgência, agência política e performance decolonial. Seriam esses, alguns indícios sobre re-existência diaspórica? Como apoiamo-nos nesses descaminhos para alcançar alternativas de intervenção sociopolítica? Qual seria a relevância da recuperação de narrativas contra hegemônicas na reescrita das histórias perdidas e invisibilizadas pelo processo de escravização, pelo racismo, pelo sexismo, pela violação de direitos? As estratégias de reinvenção de si foram discutidas por Angela Davis, quando problematiza o não direito à maternidade,

A origem de sua força não era um poder místico vinculado à maternidade, e sim suas experiências concretas como escravas. São experiências acumuladas por todas essas mulheres que labutaram sob o chicote de seus senhores, 
trabalharam para sua família, protegendo-a, lutaram contra a escravidão e foram estupradas, mas nunca subjugadas. Foram essas mulheres que transmitiram para suas descendentes do sexo feminino, nominalmente livres, um legado de trabalho duro, perseverança e autossuficiência, um legado de tenacidade, resistência e insistência na igualdade sexual - em resumo, um legado que explica os parâmetros para uma nova condição de mulher. (DAVIS, 2016, p.41).

Com essa observação de Davis, podemos perguntar sobre o direito à existência. Quem, entre mulheres escravizadas, no Brasil, pode contar histórias sobre amamentar seus próprios filhos?

Fazer conhecer nossas experiências de negação e sofrimento, mas também de conquistas como reivindicações e demandas, já em curso, é um importante pacto com a memória de Esperança Garcia e de Gertrudes Maria.

\section{Gertrudes Maria}

Gertrudes Maria, foi uma negra alforriada "sob condição", o que significava prestar serviço para os antigos donos até suas mortes. Viveu na Paraíba do século VXIII e conseguiu comprar a sua carta de alforria com uma quantia de 100 mil réis. Conhecida como a "negra do tabuleiro", Gertrude alcançou o status de quitandeira podendo, assim, garantir seu sustento. A condição de comerciante autônoma permitia uma grande mobilidade para circular pela cidade, o que lhe garantiu amizade com pessoas de todas as classes, livres, escravizadas, pobres e ricos (ROCHA, 2007). Essa mulher compreendeu as estruturas do sistema escravagista, via os limites de uma liberdade condicionada, mas que, mesmo assim, poderia lhe garantir algumas doses de autonomia.

O acordo estabelecido para a compra de sua alforria passava pelos interesses camuflados de conservação do trabalho escravo. Alforrias condicionadas, garantiam aos senhores de escravos, a continuidade dos serviços, além do controle de ações de insurgências por parte de movimentos abolicionistas. Apontar essas condições de negociações estabelecidas, é dar visibilidade para a capacidade que as mulheres negras tinham e sempre tiveram e que estão invisibilizadas na historiografia oficial. 
Em 1828 Gertrudes teve sua liberdade ameaçada por conta das dívidas adquiridas por seus "donos" - Carlos José da Costa e Maria Antonia de Mello - e seus credores recorreram à justiça pedindo que essa fosse vendida na praça em forma de quitar o saldo devedor. Por esses motivos, Gertrude aciona a justiça para apelar por um "embargo de penhora" contra seu dono Carlos José da Silva, pois já havia pago metade de sua alforria (100 mil rés) e cumpria com o pagamento prestando serviços ao mesmo. Conforme consta nos documentos de apelação ${ }^{6}$ :

Em 1826, ela tinha cerca de 30 anos, era solteira e conseguira comprar sua carta de alforria sob condição de que a dita escrava nos há de acompanhar durante as nossas vidas, prestando-me todos os serviços; e isso para que a forremos por cem mil réis valendo esta escrava duzentos mil réis pelo amor que lhe temos, pelos bons serviços que sempre nos tem prestado, e sendo que essa dita escrava falte à condição que lhe pomos de nos acompanhar como já dissemos a tornaremos cativa. (ROCHA, 2007, p. 328).

Aqui, encontramos uma mulher que vivia entre o trabalho escravo e o trabalho livre e que decidiu lutar por essa condição. Concordamos que, Gertrudes Maria compreendia que a "liberdade não era uma condição fixa, mas um alvo em constante movimento" (FILDS, 1985) e por isso ela se apressou em reagir a ação negativa que ameaçava a sua liberdade. Saiu em busca de alguém que pudesse representá-la em juízo, já que a legislação da época não permitia que escravizados ou alforriados levassem a justiça seus donos. A ação permaneceu durante quinze anos em juízo (ROCHA, 2007, p. 327).

Sobre a conclusão do processo judicial de Gertrudes, podemos afirmar que foi de luta, resistência e muita coragem, uma mulher negra alforriada que desafiou e buscou seus direitos dentro de um sistema escravista imperioso, enfrentou o silêncio imposto sobre sua nova condição social de mulher livre. Trazer a memória dessas narrativas é estender a esperança em dias melhores e possíveis de ser parte de um lugar. Mas é, sobretudo, trazer a ideia de que é mais importante entender do que lembrar, embora para entender também seja preciso lembrar (SARLO, 2007, p.18).

\section{Memória como extensão de luta e resistência}

\footnotetext{
${ }^{6}$ Apelação Cível à penhora da escrava Gertrudes, 1828-42, depositada no Arquivo do Tribunal de Justiça da Paraíba, doravante ATJPB, fl. 68. Há uma versão impressa, publicada em Mello, Albuquerque e Silva (2005). (ROCHA, 2007, p. 328).
} 
As memórias podem ser consideradas como uma caixa em que se guarda objetos especiais e de grande valor, com o passar do tempo alguns objetos podem ser tirados, outros adquiridos e assim a caixa vai se tornando um lugar que se guarda muitas lembranças sejam boas ou ruins. Em seu livro Ensinando a transgredir: a educação como prática da liberdade, bell hooks, afirma que não é fácil dar nome as nossas dores e nem criar teorias a partir desse lugar. Mas é dentro desses espaços que emergem o movimento de luta e resistência sabendo que essas narrativas construídas nos conflitos, serviram de exemplo e apoio na construção do pertencimento e fortalecimento identitário principalmente da mulher negra.

Esperança Garcia não pediu sua alforria, compreendia que naquele tempo e espaço de escravização possuía direitos e que eles deveriam ser cumpridos. De acordo com especialistas jurídicos sua carta segue um modelo que se enquadra como uma petição formal, ela se apresenta, relata os fatos e faz apelação. Considerando a carta como uma petição jurídica, a Comissão da Verdade da Escravidão Negra no Brasil (CVEN) da OAB do Piauí presidida pela advogada e professora Maria Sueli Rodrigues em parceria com a Universidade Federal do Piauí, durante dois anos realizaram um levantamento histórico e jurídico que resultou no Dossiê: "Esperança Garcia: símbolo de resistência na luta pelo direito", além de fundamentar o pedido de reconhecimento simbólico de primeira advogada do estado do Piauí para Esperança Garcia. Uma produção que dá visibilidade a uma mulher negra que denuncia o que a população negra vem sofrendo ao longo do tempo.

O potencial revolucionário feminino é percebido a partir de ações históricas promovidas por diferentes mulheres no mundo. Mulheres que em seu tempo tem transformado suas dores em luta

Mulheres que labutaram sob o chicote de seus senhores, trabalharam para sua família, protegendo-a, lutaram contra a escravidão e foram espancadas, estupradas, mas nunca subjugadas. Foram essas mulheres que transmitiram para as suas descendentes do sexo feminino, nominalmente livres, um legado de trabalho duro, perseverança e autossuficiência, um legado de tenacidade, resistência e insistência na igualdade sexual - em resumo, um legado que explica os parâmetros para uma nova condição da mulher. (DAVIS, 2016, p.41).

Mulheres que precisam ser lembradas como um símbolo de resistência feminina negra. Aqualtune, Zeferina, Luiza Mahin, Lélia Gonzalez, Maria Nascimento, Tia Ciata, Maria Carolina 
de Jesus, Mãe Beata, Beatriz do Nascimento e outras presentes, "guardiãs de sua identidade culturais e guerreiras na luta por seus direitos” (SILVA, 2009, p. 8).

Essa nova condição de mulheres tem avançado na luta pelo direito de liberdade e segurança. Leis como Maria da Penha ${ }^{7}$, a Declaração de Direitos das Mulheres ${ }^{8}$ e a Lei 13.104/20159 , a Lei do Feminicídio que somam em resultados positivos sobre a proteção e seguridade das mulheres no Brasil. Dados recentes apontam que a plena igualdade de gênero no mundo, ainda não foram alcançados. Em se tratando dos indicadores brasileiros podemos observar que a mulher negra ainda tem sofrido as desigualdades em todas as esferas sociais, educação, trabalho e segurança.

No que diz respeito aos relatos de violência registrados pelo Ligue 180, serviço oferecido pela Secretaria de Políticas para as Mulheres (SPM/PR), em 2015 foram realizados 749.024 atendimentos em comparação a 485.105 atendimentos realizados em 2014. Destes relatos $50,16 \%$ corresponderam a violência física; 30,33\%, a violência psicológica; 7,25\%, a violência moral; $2,10 \%$, a violência patrimonial; $4,54 \%$, a violência sexual; $5,17 \%$, a cárcere privado; e $0,46 \%$, a tráfico de pessoas (BRASIL, 2016, p. 11). Considerando o recorte racial entre os indicadores sociais podemos observar que lugar ocupado pela mulher negra ainda tem sido de grande vulnerabilidade. Segundo o Sistema de Indicadores Sociais (SIS) do IBGE entre os anos de 2016 e 2017.

A análise por restrição de acesso a bens em múltiplas dimensões complementa a análise monetária e permite avaliar as restrições de acesso à educação, à proteção social, à moradia adequada, aos serviços de saneamento básico e à internet. Nos domicílios cujos responsáveis são mulheres pretas ou pardas sem cônjuge e com filhos até 14 anos, 25,2\% dos moradores tinham pelo menos três restrições às dimensões analisadas. Esse é também o grupo com mais restrições à proteção social $(46,1 \%)$ e à moradia adequada $(28,5 \%)$.

\footnotetext{
${ }^{7}$ Esta Lei cria mecanismos para coibir e prevenir a violência doméstica e familiar contra a mulher, nos termos do $\S$ 80 do art. 226 da Constituição Federal, da Convenção sobre a Eliminação de Todas as Formas de Violência contra a Mulher, da Convenção Interamericana para Prevenir, Punir e Erradicar a Violência contra a Mulher e de outros tratados internacionais ratificados pela República Federativa do Brasil; dispõe sobre a criação dos Juizados de Violência Doméstica e Familiar contra a Mulher; e estabelece medidas de assistência e proteção às mulheres em situação de violência doméstica e familiar.

${ }^{8}$ No plano nacional, a discriminação contra as mulheres é proibida pela Constituição Federal. Seu artigo $3^{\circ}$ define como objetivo da República promover o bem de todos/as, sem preconceito de sexo, raça, cor e idade (entre outros), e o artigo $5^{\circ}$ prevê que homens e mulheres são iguais em seus direitos e obrigações.

${ }^{9}$ Instituiu uma nova modalidade de homicídio qualificado que prevê como crime hediondo o assassinato de mulheres por "razões da condição de sexo feminino" - ocorridas em caso de violência doméstica e/ou familiar, menosprezo ou discriminação à condição de mulher.
} 
No campo da educação, as desigualdades ainda se encontram bem acentuadas, no ano de 2016 o IBGE traz os seguintes percentuais entre a população de 25 anos ou mais de idade com ensino superior completo, $23,5 \%$ das mulheres brancas para $10,4 \%$ das mulheres pretas e pardas. Taxa de frequência escolar no ensino médio, entre mulheres brancas são de 80,1\%, para 69,3\% entre as pretas e pardas.

Como podemos observar, o fim da abolição não foi suficiente para que os negros fossem absorvidos pelo mercado de trabalho, tampouco aos espaços educacionais. As estatísticas continuam a apontar que a população negra vem enfrentando o racismo, a discriminação racial, salários inferiores, acesso à saúde precário e/ou nenhum, menor índice de emprego e as piores condições de moradia. Haveria outras possibilidades de existência para os negros?

Como nos aponta Wilson Barbosa (2009), ao citar a negligência do Estado em relação à posição do negro no mercado de trabalho, denunciando a existência do racismo estrutural que alcança e compromete as relações de vida do negro no Brasil.

\begin{abstract}
O Estado brasileiro finge não saber que a raça negra não é uma naturalidade, mas uma relação social. Enquanto relação social, ela é o elemento sustentador da exploração, porque todo êxito não-negro está alicerçado sobre a exploração do negro. A hipocrisia analítica da ciência social oficial brasileira consiste em não perceber o capital como a exploração preferencial dos negros, como a captação de sua mais-valia, como a construção de um lucro adicional sobre cadáveres negros. Por outro lado, a sobre-exploração dos negros permite viabilizar para a população branca uma redução de suas jornadas de trabalho e a perpetuação de que explorem mercados primitivos locais, constantemente reconstituídos pela esfera pública. Veja-se o aberratório dos menores infratores, dos catadores de lixo e das empregadas domésticas (BARBOSA, 2009, p.71).
\end{abstract}

Sobreviver a essas desigualdades e injustiças tem sido possível; pois, embora entendamos que existem diferentes mecanismos de bloqueio sociais construídos a fim de manter os negros em lugares subalternos, a população negra tem seguido se organizado na clandestinidade, usando brechas que permitem acessar outros lugares. Como afirma Nei Lopes, mesmo pisados, vendidos, trocados, estamos de pé... e seguimos na luta pelo direito de existir e reexistir (PALMARES, 2009). E foi desse "não-lugar" social que a população negra avançou no enfrentamento de muitos obstáculos como o racismo estrutural, as discriminações e desigualdades raciais e sociais foram 
fatores determinantes para o surgimento das organizações nas quais essa população se torna atriz e produtora de muitos Movimentos negros.

Resistimos aos tumbeiros, nos organizamos entre os quilombos, construímos nossa identidade negra na diáspora entre associações e confrarias; nos movimentos negros, nos fortalecemos. Sempre fomos organizadas! A luta por democracia e justiça social no Brasil sempre foi uma pauta defendida pela organização de mulheres negras. Mesmo que ao longo da história nossa identidade tenha sido restrita ao trabalho escravo submisso, ou corpos erotizados. As memórias de Esperança e Gertrudes provam que as mulheres negras sempre foram e são capazes de realizar grandes transformações sociais. O fragmento abaixo é parte da entrevista de Ana, quem fez parte da pesquisa de Silva e Pereira (2014).

Se você olhar a história das mulheres negras, você vai descobrir que elas sempre se organizaram. Na África você vai encontrar organizações e mulheres negras e quando as mulheres começam a chegar ao Brasil como escravas, começam a chegar as organizações. Já havia essa história, essa trajetória. Elas já se organizavam à parte dos homens e também juntamente com os homens. Então, o que nos leva à organização desde a década de 1990 é essa própria história. Apesar de nas literaturas recentes você ouvir e ler que o Movimento de Mulheres Negras se organiza pela falta de espaço entre os negros e entre mulheres parece que somos um movimento de mulheres que foi levado a isso pela impossibilidade política dos outros movimentos, essa é a primeira leitura que se faz. Mas, na verdade isso indica que as mulheres negras demandavam um tipo de protagonismo que elas se reconheciam em si, ou seja, já havia uma certeza de que a posição que a mulher tem de ocupar em uma organização política não é uma posição subsidiária. Isso não é porque as mulheres negras das décadas de 1970 e 1980 acordaram e disseram: Eu quero ser protagonista! Mas é por que existe uma cultura que foi mantida, e eu acredito que não é o ressentimento em relação a um movimento misto ou um movimento feminino, é porque a gente faz organização desde sempre ${ }^{10}$.

\footnotetext{
${ }^{10}$ Apelação Cível à penhora da escrava Gertrudes, 1828-42, depositada no Arquivo do Tribunal de Justiça da Paraíba,
} doravante ATJPB, fl. 68. Há uma versão impressa, publicada em Mello, Albuquerque e Silva (2005). (ROCHA, 2007, 
As organizações Geledés: Instituto de Mulheres Negras ${ }^{11}$ e CRIOLA ${ }^{12}$ são duas organizações de destaque na história do Movimento de Mulheres Negras e que atuam na garantia de direitos. Seus projetos, na atualidade, são construídos em parceria com órgãos internacionais, da iniciativa privada e por esferas do Estado. Esses, visam apoiar iniciativas que envolvem a emancipação do segmento incluindo diferentes faixas etárias de diferentes regiões. Não são organizações como tantas outras já que no seu histórico, inauguraram metodologias fundamentais produzindo ambiências de aprendizagens coletivas (SILVA, 2017).

As memórias individuais e coletivas permitem visitar um passado e lembrar do que já foi vivido. De acordo com Sarlo (2007), esse "lembrar" se dá dentro do conceito de pós memória, considerando como,

\begin{abstract}
A geração seguinte àquela que protagonizou os acontecimentos, ou seja, é a memória dos filhos sobre a memória dos pais. [...] a pós-memória cumpre as mesmas funções clássicas da memória: fundar um presente em relação com um passado. A relação com esse passado não é diretamente pessoal, em termos de família e pertencimento, mas se dá através do público e da memória coletiva produzida institucionalmente. (SARLO, 2007, p.97).
\end{abstract}

Essa memória coletiva como voz enunciadora de uma produção de movimento educativo na perspectiva de se re-inventar enquanto mulheres negras latinas que seguem formando uma rede de aprendizagens outras na luta, na esperança, organização de um sentimento de identidade coletivo, "fator extremamente importante do sentimento de continuidade e de coerência de uma pessoa ou de um grupo em sua reconstrução de si, (SARLO, 2007). Esperança Garcia tem sua continuidade em cada uma de nós mulheres negras afro-brasileiras, que em suas narrativas trazem as memórias de lutas e resistência dessa escrava negra brasileira.

O poema de Conceição Evaristo, A noite não adormece nos olhos das mulheres, descreve de maneira delicada a guarda e cuidado desse lugar de dor e resistência:

\footnotetext{
${ }^{11}$ Organização de mulheres negras que lutam contra o racismo e todas as formas de discriminação presente na sociedade.

${ }^{12}$ CRIOLA é uma organização da sociedade civil com mais de 25 anos de trajetória na defesa e promoção dos direitos das mulheres negras. Fundada em 1992, atua na construção de uma sociedade onde os valores de justiça, equidade, solidariedade são fundamentais. https://criola.org.br/
} 
Figura 1.

\begin{tabular}{|l|l|}
\hline A noite não adormece & {$[\ldots]$} \\
nos olhos das mulheres & A noite não adormecerá \\
a lua fêmea, semelhante nossa, & jamais nos olhos das fêmeas \\
em vigília atenta vigia & pois do nosso sangue-mulher \\
a nossa memória. & de nosso líquido lembradiço \\
A noite não adormece & em cada gota que jorra \\
nos olhos das mulheres & um fio invisível e tônico \\
há mais olhos que sono & pacientemente cose a rede \\
onde lágrimas suspensas & de nossa milenar resistência. \\
virgulam o lapso & (Conceição Evaristo, 2013) \\
de nossas molhadas lembranças. & \\
\hline
\end{tabular}

\section{À guisa de conclusão}

Consideramos, em diálogo com as/os autores aqui inseridos, que a ideia de identidade e memória não é estável e contemporaneamente desterritorializado. Esperança Garcia e Gertrudes Maria precisam ser conhecidas como parte de uma memória universal e contra hegemônica de todos e todas que se encontram empenhados na construção de novos paradigmas de mundo e de sociedade, alicerçados em relações de igualdade, justiça social e respeito integral e irrestrito à dignidade da pessoa humana.

Também produziram narrativas que se tornam células, parte de um testemunho de um tipo de ativismo pelo direito de existir, e insistir com as agendas. Somos testemunhas divididas pelo espaço-tempo, mas próximas pelas lutas que são as mesmas e que são pertinentes para o tempo presente.

Construir outras agendas a partir de uma leitura decolonial dialogando com outras narrativas femininas, que pensam outro projeto de sociedade partindo de referenciais que permitem olhar para as memórias históricas de mulheres - em sentido mais amplo - enfatizando que é possível fomentar outras vivências significativas e transformadoras. Um movimento contra o racismo e a eliminação de toda e qualquer forma de segregação, subalternização.

Esperança Garcia e Gertrudes Maria estão presente na luta anticolonial e antirracista. e, portanto, estão em cada um de nós. Mulheres negras afro-brasileiras, que acompanham nossas 
performances, nossas narrativas e compõem as memórias de luta e resistência. São células de uma recomposição que nos ajuda a dar sentido ao que somos e vislumbrar os passos seguintes.

\section{REFERÊNCIAS}

BARBOSA, Wilson do N. A Discriminação do negro como fato estruturador do poder. Revista Sankofa, USP. Número 3, página 71, 2009.

BRASIL. Plano Nacional das Diretrizes Curriculares Nacionais para a Educação das Relações Étnico-raciais e para o Ensino de História e Cultura Afro-brasileira e Africana. Brasília: SECAD; SEPPIR, jun. 2008.

DAVIS, Angela. Mulheres, raça e classe. São Paulo: Boitempo, 2016.

EVARISTO, Conceição. Insubmissas lágrimas de mulheres. B Horizonte: Nandyala, 2011.

GIDDENS, Anthony. A Constituição da sociedade. São Paulo: Martins Fontes, 2009.

IBGE. Estatísticas de gênero: responsabilidade por afazeres afeta inserção das mulheres no mercado de trabalho. In: https://agenciadenoticias.ibge.gov.br/agencia-sala-de-imprensa/2013agencia-de-noticias/releases/20232-estatisticas-de-genero-responsabilidade-por-afazeres-afetainsercao-das-mulheres-no-mercado-de-trabalho Acesso em: 6 de março de 2018.

MIRANDA, Claudia. Currículos decoloniais e outras cartografias para a educação das relações étnico-raciais: desafios político-pedagógicos frente a Lei $n^{\circ}$ 10.639/2003. Revista da ABPN • v. 5, n. $11 \cdot$ jul.- out. $2013 \cdot$ p. 100-118.

MOTT, Luiz R. B. Piauí colonial: população, economia e sociedade. Teresina: Projeto Petrônio Portela, Governo do Estado do Piauí, 1985.

PAIXÃO, Marcelo; GOMES, Flávio. Histórias das diferenças e das desigualdades revisitadas: notas sobre gênero, escravidão, raça e pós-emancipação. Rev. Estud. Fem., Florianópolis, v. 16, n. 3, p. 949-969, Dec. 2008. http://www.scielo.br/

PALMARES, Gilberto. Desigualdades Étnico-Raciais nos 120 anos da República Brasileira. In: Acervo: Revista do Arquivo Nacional. V.22 n. 2 (jul/dez. 2009). Rio de Janeiro: Arquivo Nacional, 2009. 
Panorama da violência contra as mulheres no Brasil [recurso eletrônico]:indicadores nacionais e estaduais. - N. 1 (2016) Brasília: Senado Federal, Observatório da Mulher Contra a Violência, 2016.

ROCHA, Solange Pereira da. Gente Negra na Paraíba oitocentista: População, Família e Parentesco Espiritual. Tese. Universidade Federal De Pernambuco Centro De Filosofia E Ciências Humanas Programa De Pós-Graduação Em História. Recife-PE, 2007.

SARLO, Beatriz. Tempo passado: cultura da memória e guinada subjetiva. São Paulo: Companhia das Letras; Belo Horizonte: UFMG 2007.

SILVA, Ana Beatriz da. "Coisa de mulher" e "CRIOLA": um estudo sobre aprendizagens decoloniais em ongs de mulheres negras. Dissertação Universidade Federal do Estado do Rio de Janeiro, 2017.

SILVA, Joselina. Mulheres Negras: histórias de algumas brasileiras. Cadernos CEAP Rio de Janeiro: CEAP, 2009.

SILVA, Joselina; PEREIRA, Amauri Mendes. O movimento de Mulheres Negras: escritos sobre os sentidos de democracia e justiça e social no Brasil. Belo Horizonte: Nandyala, 2014.

SOUZA, Elio Ferreira de. A carta da escrava 'Esperança Garcia' de Nazaré do Piauí: uma narrativa de testemunho precursora da literatura afro-brasileira. http://www.letras.ufmg.br/ literafro/arquivos/artigos/criticas/ArtigoElioferreiralcartaesperancagarcia.pdf Acesso em 05 de fevereiro de 2019.

WALSH, Catherine. CANDAU, Vera Maria (org)Notas pedagógicas a partir das brechas decoloniais. In: Interculturalizar, descolonizar, democratizar: uma educação "outra"? Rio de Janeiro: 7 Letras, 2016. 